\title{
Analysis on the Training Paths for Foreign-related Legal Talents Under the Opening-up of Education
}

\begin{abstract}
Zhengyi Zhang, Xiaochen Li*, Yiwei Dong
Shanghai University of Political Science and Law, Shanghai, China

*Corresponding author. Email: zzyvette@163.com

ABSTRACT

With the proposal of "Belt and Road" in our country, the scale of opening to the outside world is unprecedented with the current scale of foreign-related legal talent failing to meet the actual needs of China's Opening-up Strategy in the new era and the construction of foreign rule of law. It is an urgent issue to be solved that how to fill the gap of foreign rule of law talents and solve the dilemma of foreign legal personnel training. China has actively explored diversified talents training directions to provide think tank support for the development of foreign legal practice. Under the new pattern of comprehensive opening-up of education, it is essential to take thought on socialism with Chinese characteristics for a new era as the guide, based on the training goal of foreign-related legal talents, innovate and transform the traditional talent training mode and train a group of high-level foreign-related legal talents to serve our country's opening-up strategy.
\end{abstract}

Keywords: Opening-up of Education, Foreign-related Legal Talents, Training Mode.

\section{教育开放背景下涉外法治人才培养路径探析}

\author{
张正怡, 李霄晨 ${ }^{*}$, 董奕玮
}

\author{
上海政法学院, 上海, 中国 \\ “通讯作者. 邮箱：zzyvette@163.com
}

\begin{abstract}
中文摘要
随着我国 “一带一路” 倡议的提出，我国对外开放规模不断扩大，当前现有的涉外法治人才规模已经不能满足 新时代对外开放和涉外法治建设的实际需要。如何填补我国涉外法治人才缺口并解决当前涉外法治人才培养 困境是亟待解决的紧迫问题。我国在教育对外开放的政策支持下积极探索多元化人才培养方向为涉外法律实 务发展提供智库支持。在全面开放教育新格局下，我国对涉外法治人才培养应当以习近平新时代中国特色社会 主义思想为引领, 立足于我国涉外法治人才培养目标, 创新转变传统人才培养模式, 培养一批为我国对外开放 战略服务的高水平涉外法治人才。
\end{abstract}

关键词：教育对外开放；涉外法治人才; 培养模式. 


\section{1. 改革开放以来我国高等教育事业开放与涉 外法治人才培养}

\section{1. 高等教育国际交流发展}

经济的高速发展离不开人才的贡献，人才的培养 依靠离不开先进的教育制度。于是乎, 高等教育改革 开放问题成为了改革开放后重点关注的问题之一。改 革开放后的高等教育国际交流发展进程可以分为以 下四个阶段:

\subsection{1. 初步建立阶段}

党的十一届三中全会确立改革开放政策后，我国 转变了高等教育政策“引进来”的主基调。[1]党的十三 大和十四大期间针对教育改革发布多个文件, 对于教 育体制改革给予高度重视。文件中明确指出“新技术 革命条件下高等教育应当加强对外交流”, 为我国高 等教育国际交流的发展奠定了基础方向并展现了我 国对于高等教育国际交流的鲜明立场。

\subsection{2. 基本稳定阶段}

党的十四大召开后, 国务院发布《中国教育改革和 发展纲要》强调应当把加强国际教育交流与合作作为 该历史阶段的主要目标和任务之一。党的十五大后, 教育部发布《面向 21 世纪教育振兴行动划》, 针对 我国教育战略以及教育体系作出全方位部署, 为实现 十五大所确定的跨世纪伟大教育工程目标作准备。

\subsection{3. 巩固提高阶段}

由于我国成功加入世界贸易组织（WTO），党的 十六大对于教育振兴行动计划提出了新的期望与目 标。即在打开服务教育贸易的背景下, 我国应当推进 全方位、多领域、高层次国际合作与交流格局, 加强 与世界一流大学的密切联系和学术合作, 并且通过中 国特色教育的输出打造出中国教育品牌。

\subsection{4. 发展新阶段}

党的十八大以来, 我国高等教育国际交流处于中 国特色新发展阶段。我国印发了多份教育改革文件为 我国高等教育对外开放工作制定具体部署, 不仅从教 育主体着手加强人才培养, 还要着力营造有利于高等 教育国际交流开放的氛围。《中国教育现代化 2035》 更是将开创教育对外开放新格局作为现阶段至 2035 年的十大战略任务之一, 并提出加强国际交流互鉴来 推进和完善我国教育体制的建设并促进中国特色教 育发展的传播。

\section{2. 涉外法治人才培养状况}

在推动构建全球治理体系和国际法治新制度的时
代背景下, 涉外法治人才的培养具有紧迫性和必要性。 2011 年《中央政法委员会关于实施卓越法律人才教育 培养计划的若干意见》基础版和 2018 年进阶 2.0 版 本中, 指出培养一批涉外法律卓越人才是适应当今社 会主义法治国家建设的核心任务, 并强调我国应当将 培养高层次涉外法治人才、构建涉外法治人才培养新 格局作为现阶段教育改革的核心目标, 为国家建设发 展提供所需要的高素质涉外法治人才, 为我国“一带 一路”等战略服务。

我国为贯彻涉外法治人才培养计划, 增设了卓越 法律人才教育培养基地, 将全国 22 所高校设为培养 基地, 结合各校的法学人才培养优势和特色为我国涉 外法治人才培养提供多样化培养模式。此外, 我国通 过鼓励支持高校与法律实务部门联合合作, 重点建设 共享的示范性法学合作实践教学基地的方式, 为涉外 法治人才的培养搭建理论教学和法律实践的桥梁, 促 进培养高质量涉外法治人才目标的实现。

\section{2. 我国涉外法治人才面临的巨大缺口与当前 培养困境}

\section{1. 我国涉外法治人才缺口}

尽管改革开放以来，我国大力鼓励高等教育对外 开放改革并且支持对涉外法治人才的培养，但是我国 当前涉外法治人才的数量和质量远远赶不上我国经 济发展和综合国力提升的速度, 远远不能满足新时代 对外开放和涉外法治建设的实际需要。

根据《关于建设涉外律师人才库的通知》建立的全 国涉外律师人才查询系统中有 985 名律师, 约占全国 执业律师总数的 $0.2 \%$ 。通过数据突出表明我国当前 涉外法治人才面临明显巨大缺口, 我国现有涉外法治 人才库不能适应高水平对外开放格局和日益多元化 的涉外法律服务需求。巨大的市场需求给我国涉外法 律人才的业务拓展提供了契机, 然而涉外法律人才的 匮乏一直是我国法律服务行业的软肋[2]。

\section{2. 涉外法治人才培养困境}

\subsection{1. 涉外法治人才语言转换能力欠缺}

涉外法治人才因为涉外的特殊性，在涉外法律服 务中应当以英语或其他外语作为主要工作语言, 因此 跨语言之间的交流是涉外法律实务中经常涉及的一 个难点问题。然而据调查, 本土律师较外国律师的劣 势不在于涉外法律知识, 而是法律英语语言的应用能 力。

由于不同语言的转换问题, 涉外律师在涉外法律 服务的谈判协商中可能出现因词不达意而矛盾激化 的情形; 涉外律师在法律文书撰写中, 可能出现对于 法律术语的不熟悉或者由于法律翻译的不严谨而导 致不能确切领会或误解互相表达的情形; 在案件审判 
中，涉外律师还可能出现意思表示不清的尴尬情形。 故如何适应全外语的工作环境、熟练掌握外语技能以 突破涉外法治人才培养中的语言瓶颈问题亟待解决。

\subsection{2. 涉外法治人才培养同质化现象严重}

涉外法治人才是“精英化”的高端复合型人才，故 对于涉外法治人才的培养需要进行构建有针对性的 专门培养体系和科学化体制机制。然而目前整个法学 专业人才培养同质化的现象仍然十分普遍, 各校皆适 用单一的涉外法治人才培养模式, 并且在总体上尚未 形成系统性的特色涉外法治人才培养体系, 这显然不 符合涉外法治人才培养的要求。

由于培养价值和目标的不同, 则相比于传统法治 人才培养体系, 涉外法治人才培养体系应当融合国际 视野和中国视角。[3]高校作为涉外法治人才培养的摇 篮, 应当在传统培养体系的经验基础上依据涉外法治 人才培养目标作出科学化调整, 积极探索出一套符合 涉外法律实务发展需要的涉外法治人才培养体系。

\subsection{3. 涉外法治理论教育与实践教学分离}

涉外法治人才的培养离不开实践活动, 但是由于 实践教学较多流于形式, 以至于我国实务部门的涉外 法治实践资源无法转化为国际法教学资源, 出现理论 教学和实践教育相互独立运行的状态。此外, 我国现 阶段高校对于实践教学投入力度不足, 目前我国远程 教育输出也正处于探索阶段, [4]现高校仍不具备将在 校学生大规模送往国际组织实习的条件。

涉外法治人才的培养需要要打破高校和涉外实务 部门之间的体制壁垒, 将涉外实务部门的优质实践教 学资源引进高校。并且, 高校在与涉外实务部门进行 合作共享学术资源的同时应当推进其在涉外法治人 才培养工作中发挥重要作用, 通过进一步加强联系并 建立合作的基础上, 为学生提供更多学习交流平台以 促进法治人才培养工作的全面开展。

\section{3. 教育开放背景下涉外法治人才培养方向}

\section{1. 我国教育对外开放趋势与背景}

近年来, 我国教育对外开放的蓝图更加清晰, 我国 教育开放规模不断扩大, 我国教育开放质量也不断提 高。在教育对外开放的政策支持下，中国的教育合作 伙伴已遍布全球, 是世界最大的国际学生生源国和亚 洲最大的留学目的地国。

2019 年《加快推进教育现代化实施方案（20182022 年）》和《中国教育现代化 2035》为我国教育 对外开放提供了战略化安排, 对于我国近阶段的教育 改革提供了基础方向, 明确了当今和今后一段时间推 进教育对外开放的要求和理念。

2020 年教育部等八部门印发《关于加快和扩大新
时代教育对外开放的意见》, 着眼于加快推进我国教 育现代化和培养更具全球竞争力的涉外法治人才并 积极向国际社会贡献教育治理中国方案。

在我国教育开放背景下，高校应当立足于我国涉 外法治人才培养目标, 创新转变传统人才培养模式, 加强人才培养国际化交流与合作, 培养一批为我国对 外开放战略服务的高端涉外法治人才。

\section{2. 国际组织创新人才培养方向}

国际组织是全球治理变革的协调中心，是体现和 提升国家软实力的特殊平台, [5]在涉外法治人才培养 体系中占据着举足轻重的地位。我国高校应当充分利 用国际资源平台，通过与国际组织进行多方位合作来 助力涉外法治人才培养。

国际组织人才培养将实行“高校+国际组织”的联 合培养方式，不仅将与国际组织签订合作协议共享国 际资源, 而且将建立多元化国际组织人才培养输送渠 道, 并通过整合各高校的自身学科优势以及优质资源 来培养国际组织储备人才以提高中国在国际组织中 的话语权和影响力,以实现我国参与全球治理和推进 构建人类命运共同体提供中国智慧和中国方案的目 标。

\section{3. 涉外律师方向硕士人才培养方向}

在当今经济全球化的转折点下, 加强涉外法律服 务和培养涉外法治人才成为了新时代使命，提升中国 国际话语权并且将中国制造推向世界离不开涉外法 律服务人才。2021 年我国发布《关于实施法律硕士专 业学位 (涉外律师) 研究生培养项目的通知》, 通过 选取 15 所高校实施涉外法律专业硕士研究生培养项 目进行试点，支持高校积极探索具有中国特色的涉外 法治人才培养新模式。

涉外律师方向硕士人才培养将实行“高校+行业” 的联合培养方式, 通过和涉外法律实务部门的联合培 养, 为涉外律师人才培养提供充足的实践岗位以及稳 定的实践机会, 将理论与实践并行贯彻始终来培养一 支善于处理国际法律事务的高层次涉外律师队伍为 国家发展建设提供智力支持。

\section{4. 教育开放背景下涉外法治人才培养模式}

探索具有中国特色的涉外法治人才培养模式是一 项系统化的工程，应当从多方面着手规划培养计划。 我国打造世界一流涉外法治人才梯队目标的实现需 要围绕涉外法治人才培养目标, 从以下几个基础方面 开始逐个击破。 


\section{1. 构建一体化涉外法治人才课程体系}

\subsection{1. 根植中国特色社会主义法治理论课程}

我国加强涉外法治人才培养的最终目的是通过培 养一批具有国际视野的高层次涉外法律人才, 以国家 战略需求为导向, 在全球化竞争中提高我国国际话语 权以及国家竞争力。因此, 涉外法治人才必须加强自 身政治素质培养, 毫不动摇坚持党的领导, 坚持习近 平中国特色社会主义思想, 维护我国国家主权和利益。

高校应当有针对性地加强彰显中国特色社会主义 法治理论与实践成果的法学教材体系建设, 将中国特 色社会主义法治理论根植于学科课程体系, 将社会主 义核心价值观贯穿于涉外法治人才培养体系, 培养具 有 “中国心” 的法律人才, 使其能够为国家法治建设 服务。

\subsection{2. 优化国际法课程设置}

由于涉外法治人才的特殊性, 除了国际关系基础 理论、国际公法原理、国际私法原理、国际经济法原 理等国际法核心课程之外, 涉外法治人才课程必须设 置国际法特色必修课, 例如世界贸易组织法、国际商 法、国际投资法、国际商事调解与仲裁法等特色专业 课程。相比于一般法治人才, 涉外法治人才应当具备 扎实的法律功底以及广阔的国际视野, 通过全面掌握 有关国际法的基本理论和原则, 提高在实践中解决相 关国际法律问题的能力。

高校在涉外法治人才的课程设置方面, 尤其是在 本科教学中, 应当转变传统 “三国法” 的模式, 建立 起立体化的国际法课程设置。由于国际法学科的与时 俱进性，涉外法治人才培养在聚焦于 “三国法” 的同 时, 要不断完善和优化国际法课程以确保国际法课程 的完整性和系统性。

\subsection{3. 引入全英语国际法专业课程}

由于现今英语是全球通用的第一大语言, 而跨国 贸易往往发生在境外领域或外国当事人之间, 故涉外 法治人才首先必须熟练掌握英语并确保能将英语作 为主要工作语言。

具有较好的外语沟通能力和跨文化交流能力, 能 够在法律实务中熟练运用英语是涉外法治人才的基 本培养要求。高校在制定教学模式以及设置相应课程 时, 必须确保英语贯穿于教学体系中, 不仅将全英语 模式融汇应用于国际法学课程中, 原则上全英语国际 法专业课程更应当采用英文原版教材以英语进行教 学, 这也是涉外法治人才作为复合型人才的题中应有 之义。

\subsection{4. 融汇特色涉外实务性课程}

涉外实务性课程是以实务案例等形式分析运用理
论知识的教学模式, 强调理论与实践的有机结合。通 过实务性课程可以培养学生的法治实务思维和实践 能力, 故设置相关实务性课程是涉外法治人才培养的 重点课程设置之一。

我国高校应当加快建立与涉外法律服务机构、行 业协会等机构的合作关系并制定联合培养计划，则高 校可以合理分配该优质资源开设案例研究课程、法律 实务操作实训等实务课程, 并且邀请我国涉外法律服 务行业的实务工作者来进行实践教学, 通过其处理涉 外法律问题的直接经验以及一手资料来提供专业的 实践指导。

\section{2. 建立实践导向的涉外法治人才培养机制}

鉴于法学学科是实践性很强的学科, 法学教育不 能仅仅停留在课本上。涉外法治人才的培养不应拘泥 于传统课堂所传授的知识，而应当建立实践导向的培 养机制，注重实践应用的必要性。

涉外法治人才培养模式中的循序渐进式实践训练 可以分为以下三个阶段:

第一个阶段是对于涉外法律文书写作和法律检索 的实践教学与训练。法律文书是展现最终成果的一种 形式, 也是反映法律人思维和逻辑的直观路径。鉴于 涉外法律文书的语言特殊性, 通常需要英语甚至其他 语言进行陈述和答辩，因此在特定词汇的表达方式以 及措辞上都需要㽎酌以满足司法实践的需要。同样, 涉外法律检索也是不可或缺的必备技能并且相当有 难度。涉外法治人才如何高效检索外国判例或案例以 提取有效信息，如何快速检索他国的现行法律以进行 外国法查明都是高校生于在校期间便需要加强的实 践训练。

第二个阶段是实务模拟训练。近年来，以国际模拟 法庭、国际模拟仲裁为代表的国际类模拟竞赛 (Moot) 在一定程度上为中国学生走向国际舞台提供了平台, [9]为在校学生提供实践训练的机会, 以点带面全方位 提高自身的专业应用型技能。例如, 上海政法学院主 办的 2021 年第十一届 Moot Shanghai 国际商事模拟 仲裁庭上海邀请赛吸引了来自全球各知名法学院的 400 多名学生参赛, 为参赛选手提供了一个展现自我 的平台。国际模拟竞赛最大的优势在于结合国际环境 大背景并聚焦于当下国际热点问题，以全英语的方式 运用国际规则进行分析, 通过与其他学校的学生直接 互动的方式在比赛中以赛代练快速成长, 不断提升实 战技能和专业水平。

第三个阶段是校外涉外专业实习。高校法学生校 外实习是培养涉外法治人才的关键环节，也是培养法 学生实践能力和创新精神的必由之路。各高校应当积 极与联合培养单位联合组织专业实习, 通过与涉外法 治实务部门人才交流使学生对于涉外法律服务业有 一个真切的感受。此外，高校可以与国际组织、跨国 公司、涉外律师事务所等建立定期实习机制, 为涉外 
法治人才的培养提供实践的平台, 打破高校与涉外法 治实务部门的人才流通壁垒。

\section{3. 塑造涉外法治人才的法律实务思维}

创新课程体系和安排实践训练是通过高等院校辅 助的培养模式, 属于外因范畴; 而对法律学生的实务 思维能力的培养则是涉外法治人才自身能力的突破, 属于内因范畴。高校应当从实务课程和实践活动两方 面着手为法学生建立涉外法律实务思维体系, 提升涉 外法治人才的涉外法律服务的实践能力。

一方面要加快培养发展法律应用型人才, 在实务 课程指导下培养法律思维能力。法律实务思维的塑造 离不开法律实务人士的指导, 职业法律人的讲解真实 的涉外案件、分析存在的问题、总结法律障碍的全过 程, 这其实就是建立一个法律实务思维模型的阶段, 也是学生培养法律实务思维的途径。法律实务人士的 指导对于学生的法律实务思维的塑造更加具有针对 性和目的性，促成了一个“指导-塑造-再指导”的良性 循环, 对于涉外法治人才法律实务思维的培养起到了 积极推动的作用。

另一方面要坚持锻炼法律实务思维。法律校外实 习的目的是检验学生法律专业知识的掌握和运用能 力, 并且通过自身实践培养法律实务思维能力。法律 实务思维的塑造是一个循序渐进的过程, 增强实务思 维能力是培养涉外法治人才的的客观要求。高校应当 转变教学理念, 从重视法学理论教育转向重视法学实 践运用能力, 并将实务思维培养贯彻整个涉外法治人 才培养模式的始终。

\section{5. 结语}

中国改革开放 30 年以来，从“走出去”战略到共建 “一带一路”倡议，构建人类命运共同体，始终秉持共 商共建共享的全球治理观，在积极推动全球开放合作 中不断提升我国的国际地位和国际影响力。随着国际 化的风险挑战愈来愈多, 中国对高端涉外法治人才的 需求越来越紧迫。全面开放教育新格局下, 我国对涉 外法治人才培养应当以习近平新时代中国特色社会 主义思想为引领, 立足于我国涉外法治人才培养目标, 创新转变传统人才培养模式, 培养一批为我国对外开 放战略服务的高水平涉外法治人才。

\section{REFERENCES}

[1] Jiqiao Zhang, Baocun Liu, The Historical Evolution and Basic Experiences of the Opening-up Policies of Higher Education during the Seventy Years since the Foundation of P.R.China in 1949, Journal of Higher Education, vol.40, 2019(08), pp.9-17.

[2] Zhengyi Zhang, The Education Status of Legal English and Talent Training in China, Fa Lv Yu Yan Xue Shuo, 2009(02), pp.66-71.
[3] Zan He, The Innovation of Mechanism for the Cultivation of International Legal Professionals in China-On the Base of curriculum system construction, China Legal Education Research, 2017(02), pp.3-11.

[4] Anbang Xie, Lei Jiao, Review and reflection on the Opening-up and development of China's Higher Education since China's Accession into WTO, Teacher Education Research, vol.22, 2010(05), pp.6-13.

[5] Huikang Huang, Promote the Construction of Highquality Foreign-related Legal Talents Team from the Height of the Strategy, Chinese Review of International Law, 2020(03), pp.10-18.

[6] Xiaohong Liu, The Mission of Universities of Political Science and Law under the Background of Comprehensively Advancing the Rule of Law in China-Taking the Legal Education Practice of Shanghai University of Political Science and Law as an Example, Legal Education Research, vol.23, 2018(04), pp.69-81. 